\title{
INTERRELAÇÃO ENTRE FREQUÊNCIA DE ANTICORPOS ANTI-LEPTOSPIRA SPP. E EXAMES HISTOPATOLÓGICOS (HEMATOXILINA-EOSINA E WARTHIN-STARRY) EM SUÍNOS ABATIDOS NO SEMIÁRIDO PARAIBANO
}

\author{
Í.L. Figueiredo ${ }^{1}$, S.S.S. Higino ${ }^{1}$, C.J. Alves ${ }^{1}$, C. Del Fava ${ }^{2}$, M.E. Carretero' ${ }^{2}$, S.S. Azevedo ${ }^{1}$ \\ ${ }^{1}$ Universidade Federal de Campina Grande, Centro de Saúde e Tecnologia Rural, Unidade Acadêmica de \\ Medicina Veterinária, Av. Universitária s/nº, CEP 58700-970, Patos, PB, Brasil. E-mail: sergio.azevedo@ \\ pq.cnpq.br
}

\section{RESUMO}

Este trabalho foi realizado em suínos abatidos no Município de Patos, Estado da Paraíba, Brasil, com o objetivo de determinar a frequência de anticorpos anti-Leptospira spp., comparando os achados sorológicos com exames histopatológicos de rim, fígado, ovário e útero. A soroaglutinação microscópica foi realizada em 126 animais. Os exames histopatológicos realizados em cortes de fígado, rim, ovário e útero, corados pela hematoxilina-eosina (HE), foram realizados em 20 animais escolhidos aleatoriamente, sendo 10 do grupo com títulos $\geq 100$ e 10 do grupo com títulos < 100. Paralelamente, foi realizada pesquisa direta de leptospiras pela técnica de Warthin-Starry em amostras de rim de todos os animais soropositivos e nos 10 animais soronegativos submetidos à HE. Dos 126 animais examinados, 18 (14,6\%) foram soropositivos, com predominância de reações para o sorovar Autumnalis (11 animais; 8,73\%). Quatro animais soropositivos e dois animais soronegativos apresentaram infiltrado inflamatório e necrose de graus variados em um dos rins e no fígado. Os ovários e úteros examinados não apresentaram lesões. A pesquisa direta de leptospiras pela técnica de Warthin-Starry não revelou animais positivos em nenhuma amostra testada. Em face da soropositividade encontrada (14,6\%), sugere-se a importância da conscientização por parte dos produtores acerca da implantação de medidas de prevenção adequadas com o objetivo de impedir, ou pelo menos diminuir, a disseminação das leptospiras em suínos e, consequentemente, bloquear a possível transmissão do agente para os seres humanos.

PALAVRAS-CHAVE: Leptospirose suína, soroaglutinação microscópica, exames histopatológicos, Warthin-Starry.

\begin{abstract}
INTERRELATION BETWEEN FREQUENCY OF ANTI-LEPTOSPIRA SPP. ANTIBODIES AND FINDINGS OF HISTOPATHOLOGICAL EXAMINATIONS (HEMATOXYLIN-EOSIN AND WARTHIN-STARRY) IN PIGS SLAUGHTERED IN THE SEMIARID OF PARAIBA STATE, NORTHEASTERN BRAZIL. This work was conducted in slaughtered pigs in Patos County, Paraiba State, Brazil, with the aim to determine the frequency of anti-leptospira antibodies and to compare the serological findings with the histopathological findings of kidney, liver, ovary and uterus. The microscopic agglutination test (MAT) was performed on 126 animals. The histopathological examination performed in sections of livers, kidneys, ovaries and uteruses stained with hematoxylineosin (HE) was conducted in 20 randomly chosen animals (10 from group with serological titer $\geq 100$ and 10 from group < 100). Parallel to this, a direct search for leptospires was carried out by Warthin-Starry technique in kidney samples from all seropositive animals and in the 10 seronegative animals submitted to HE. In the 126 animals examined, 18 (14.6\%) were seropositive, with prevalence of reactions to Autumnalis serovar (11 animals; 8.73\%). Four seropositive and two seronegative animals showed different degrees of inflammatory infiltrate and necrosis in liver or kidney. The ovaries and uterus no showed lesions. Direct analysis of leptospires by the WarthinStarry technique did not reveal positive animals in any sample tested. The rate of seropositivity found $(14.6 \%)$ suggests the importance of awareness by producers about the implementation of
\end{abstract}

${ }^{2}$ Instituto Biológico, Centro de Pesquisa e Desenvolvimento de Sanidade Animal, São Paulo, SP, Brasil. 
preventive measures aimed at preventing, or at least reducing the spread of leptospiras in pigs and thereby blocking the possible transmission of the agent to humans.

KEY WORDS: Swine leptospirosis, microscopic agglutination, histopathological examination, Warthin-Starry.

\section{INTRODUÇÃO}

A leptospirose é uma das mais importantes zoonoses de ocorrência mundial, de curso agudo ou crônico, que acomete os animais domésticos, silvestres e o homem. Desta maneira, assume considerável importância como problema econômico e de saúde pública (Faine et al.,1999; MaIlloux, 2001). A infecção é causada por diferentes sorovares de espiroquetas morfologicamente e fisiologicamente semelhantes, porém, antigênica e epidemiologicamente distintas, onde todas pertencem ao gênero Leptospira spp., e são encontradas em quase todos os países (BLAHA, 1995; LeFEBVRE, 2004).

Os suínos são suscetíveis a vários sorovares, sendo considerados hospedeiros mantenedores dos sorovares Pomona, Bratislava e Tarassovi, e hospedeiros acidentais dos sorovares Icterohaemorrhagiae, $\mathrm{Ca}$ nicola, Autumnalis, Hardjo e Grippotyphosa (FAINE, 1982; ElLIS, 1992; ElLIS, 2006). Quando os suínos comportam-se como hospedeiros de manutenção, há uma adaptação hospedeiro-parasita onde as leptospiras são mantidas no trato urinário por longos períodos, sendo eliminadas pela urina em condições de viabilidade para infectar outros animais (OLIVEIRA, 1999). Os sorovares Pomona, Icterohaemorrhagiae, Tarassovi, Canicola, Gryppotyphosa e Bratislava são os mais frequentemente encontrados infectando e causando a doença nos suínos. Dentre esses, os quatro primeiros já foram isolados de suínos no Brasil (SOBESTIANSKY etal., 1999). Em suínos, a infecção é uma importante causa de perdas econômicas por distúrbios reprodutivos em todas as partes do mundo, principalmente para o sistema de criação industrial praticado em países do hemisfério norte, Austrália, Nova Zelândia, Argentina e Brasil. Por vezes o agente está associado com a forma clínica da doença, no entanto, evidências sorológicas ratificam um estado subclínico após exposição à infecção (ELLIS, 2006; JACKSON; COCKCROFT, 2007).

Inquéritos sorológicos realizados por LARSSON et al. (1984) em 500 suínos abatidos nos estados de São Paulo, Paraná e Santa Catarina evidenciaram 8,40\% de animais soropositivos. No Rio Grande do Sul, o sorovar Pomona já foi isolado de fetos abortados e de portadores sadios abatidos em frigorífico (OLIVEIRA, 1988). FARIA et al. (1989) revelaram frequência de $7,70 \%$ de animais soropositivos em 610 matrizes provenientes de 63 granjas tecnificadas das microrregiões de Viçosa e Ponte Nova, no Estado de Minas Gerais. SHIMABUKUROet al. (2003) consideraram maior importância epidemiológica no Brasil para os sorovares Icterohaemorrhagiae, Autumnalis, Djasiman e Hebdomadis. No Estado de São Paulo, AzEvedo et al. (2006), em uma granja de suínos com 164 fêmeas, encontraram $16,5 \%$ soropositivas para pelo menos um sorovar de uma coleção de 24 testados, e os mais frequentes foram Hardjo (Hardjobovis), com $54,2 \%$ dos animais sororreagentes. Outros sorovares reagentes e suas respectivas frequências foram Shermani $(16,6 \%)$, Bratislava $(12,5 \%)$, Autumnalis $(12,5 \%)$ e Icterohaemorrhagiae $(4,2 \%)$.

Em suínos, uma das principais causas de condenação de rins em frigoríficos inclui lesões caracterizadas por focos branco-acinzentados de um a $3 \mathrm{~mm}$ de diâmetro, predominantemente corticais (Drolet et al., 2002; Hashimoto et al., 2008). Essas lesões refletem os quadros de nefrite intersticial comumente encontrados em animais infectados por leptospiras (WANG et al., 1999; Delbem et al., 2002), no entanto, CHAPpel et al. (1992) verificaram que $7,5 \%$ dos suínos examinados não apresentaram tais alterações e estavam infectados, sugerindo que essas lesões não são indicadores adequados de infecção por Leptospira spp.

Este trabalho teve como objetivos determinar a frequência de anticorpos anti-Leptospira spp. em suínos abatidos no Município de Patos, Estado da Paraíba, Brasil e realizar exames histopatológicos, com o propósito de avaliar a ocorrência de lesões renais, hepáticas, uterinas e ovarianas associadas à infecção, bem como identificar o agente através da técnica de pesquisa direta Warthin-Starry.

\section{MATERIAL E MÉTODOS}

Foram utilizados 126 suínos de ambos os sexos, adultos, abatidos no matadouro público de Patos, PB, nos meses de setembro a novembro de 2009. Amostras de sangue foram colhidas durante a fase de sangria em tubos de $10 \mathrm{~mL}$, sem anticoagulante, para a realização da sorologia. O sangue foi centrifugado a 10.285 x g por 10 minutos para a obtenção do soro que foi acondicionado em microtubos de $1,5 \mathrm{~mL}$ e armazenado a $-20^{\circ} \mathrm{C}$ até o processamento. O diagnóstico da infecção por Leptospira spp. foi realizado no Laboratório de Doenças Transmissíveis (LDT) da Universidade Federal de Campina Grande, através da técnica da soroaglutinação microscópica (SAM), de acordo com a metodologia descrita por MYers (1985). Foram utilizados como antígenos 24 
sorovares de Leptospira spp., sendo 22 patogênicos e dois saprófitas, mantidos em meio de cultura artificial pelo LDT. Os sorovares de Leptospira spp. utilizados foram: Leptospira interrogans sorovares Australis, Bratislava, Autumnalis, Bataviae, Canicola, Sentot, Grippotyphosa, Hebdomadis, Copenhageni, Pomona, Pyrogenes, Wolffi e Hardjo (Hardjoprajitno); L. borgpetersenii sorovares Castellonis, Whitcombi, Tarassovi, Javanica e Hardjo (Hardjobovis); L. kirshneri sorovares Butembo e Cynopteri; L. inadai sorovar Icterohaemorrhagiae; L. noguchii sorovar Panama; L. santarosai sorovar Shermani; e L. biflexa sorovares Andamana e Patoc. A leitura da reação foi realizada em microscópio óptico (Jena Zeiss) com condensador de campo escuro (MCE), com objetiva (Epiplan) 20x/0,2 e ocular de 10 no aumento de 200 vezes, sendo avaliado o grau de aglutinação. Inicialmente, os soros foram diluídos em 1:100 e aqueles que apresentaram $50 \%$ ou mais de aglutinação foram considerados positivos. Posteriormente, os soros positivos foram diluídos geometricamente na razão dois para determinação do título, onde se considerou como título final a recíproca da maior diluição que apresentou pelo menos 50\% de leptospiras aglutinadas. Para animais que apresentaram reações para dois ou mais sorovares, considerou-se o sorovar com maior título.

Durante a evisceração, foram colhidos fragmentos de rim e fígado de todos os animais, e das fêmeas foram coletados também fragmentos de útero e ovário. Os fragmentos foram fixados em formol neutro a $10 \%$ (formol tamponado) e identificados com código correspondente à amostra sanguínea de cada animal para posterior cruzamento com os resultados da sorologia. A verificação da ocorrência de lesões foi realizada por amostragem. Foram formados 2 grupos de 10 animais e sorteados aleatoriamente: A) animais soropositivos e B) soronegativos na SAM. Após a fixação, as amostras dos dois grupos foram processadas no Laboratório Patologia Animal do Hospital Veterinário da Universidade Federal de
Campina Grande, ondeforam clivadas em aproximadamente $0,5 \mathrm{~cm}$ deespessura eincluídas em parafina. Cortes de aproximadamente $5 \mu \mathrm{m}$ foram obtidos em micrótomo vertical e corados pela hematoxilinaeosina (HE). Após o processamento, foi realizada a leitura das lâminas em microscópio óptico (aumento de até 400x). Amostras de rim de todos os animais positivos na sorologia e amostras de rim do grupo de animais soronegativos, submetidos à $\mathrm{HE}$, fixadas em formol neutro a $10 \%$ e também emblocadas em parafina, foram enviadas ao Instituto Biológico, São Paulo, onde foram submetidas à técnica de WarthinStarry para pesquisa direta de detecção do agente. As técnicas HE e Warthin-Starry foram realizadas segundo os métodos descritos por Tolosa et al. (2003) e Young (1969), respectivamente.

Para a comparação da proporção de sorovares reagentes foi utilizado o teste do qui-quadrado de aderência, e para a comparação da frequência de anticorpos antileptospira com os resultados dos exames histopatológicos foi utilizado o teste do qui-quadrado (Siegel; Castellan Junior, 2006). O nível de significância adotado foi de $5 \%$ e as análises foram efetuadas com o programa SPSS for Windows versão 13.0 .

\section{RESULTADOS}

Das126 amostras submetidas àSAM, 18 reagiram para um ou mais sorovares empregados na diluição 1:100, resultando em uma soropositividade de $14,6 \%$. O sorovar mais frequente foi o Autumnalis, com $11(8,73 \%)$ soros reagentes $(p=0,030)$. Também foram constatadas reações sorológicas para os sorovares Copenhageni com dois soros reagentes $(1,58 \%)$, Sentot, Butembo, Pomona, Tarassovi e Cynopteri com um soro reagente para cada sorovar, representando $0,79 \%$. A reação que apresentou o maior título (800) ocorreu para o sorovar Autumnalis (Tabela 1).

Tabela 1 - Distribuição de títulos de anticorpos antileptospiras em suínos soropositivos abatidos no matadouro público de Patos, Paraíba, segundo os sorovares infectantes, no período de setembro a novembro de 2009.

\begin{tabular}{lccccr}
\hline \multirow{2}{*}{ Sorovar } & \multicolumn{3}{c}{ Título } & Total (\%) \\
\cline { 2 - 5 } & 100 & 200 & 400 & 800 & $11(8,73)$ \\
\hline Autumnalis & 1 & 6 & 3 & 1 & $2(1,58)$ \\
Copenhageni & 1 & 1 & 1 & $1(0,79)$ & $1(0,79)$ \\
Sentot & 1 & & & $1(0,79)$ \\
Butembo & & 1 & & $1(0,79)$ \\
Pomona & & 1 & 1 & $1(0,79)$ \\
Tarassovi & 3 & 5 & 1 & $18(14,6)$ \\
Cynopteri & & & &
\end{tabular}


Tabela 2 - Condição sorológica em suínos abatidos no matadouro público de Patos, Paraíba, com e sem lesões histológicas sugestivas de leptospirose, no período de setembro a novembro de 2009.

\begin{tabular}{|c|c|c|c|c|c|}
\hline \multirow{3}{*}{ Lesões histológicas } & \multicolumn{4}{|c|}{ Condição sorológica } & \multirow{3}{*}{ Total (\%) } \\
\hline & \multicolumn{2}{|c|}{ Soropositivo } & \multicolumn{2}{|c|}{ Soronegativo } & \\
\hline & $\mathrm{N}$ & $\%$ & $\mathrm{~N}$ & $\%$ & \\
\hline Presentes & 4 & 40,0 & 2 & 20,0 & $6(30)$ \\
\hline Ausentes & 6 & 60,0 & 8 & 80,0 & $14(70)$ \\
\hline Total (\%) & 10 & 50,0 & 10 & 50,0 & 100,0 \\
\hline
\end{tabular}

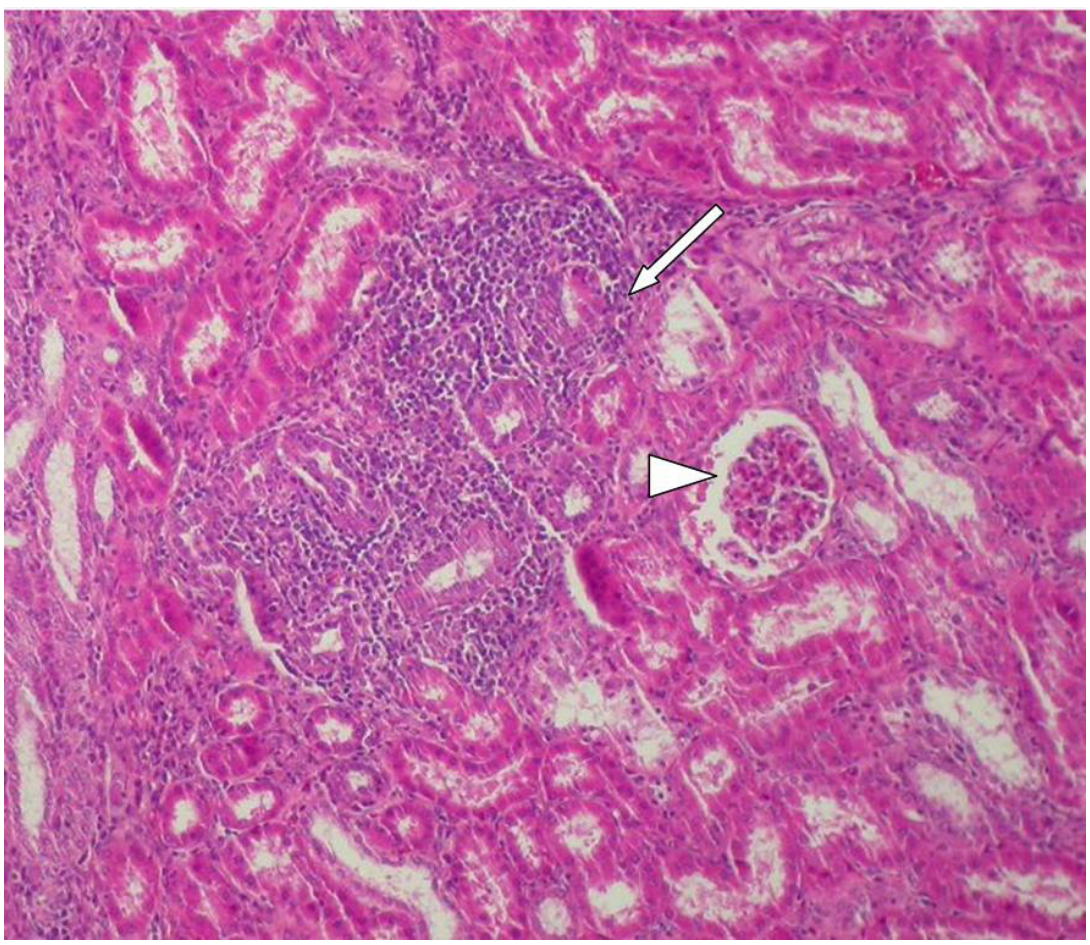

Fig. 1 - Corte histológico de parênquima renal mostrando atrofia glomerular, espessamento discreto da cápsula de Bowman (cabeça de seta) e infiltrado inflamatório mononuclear com necrose do epitélio tubular (seta) característico da nefrite intersticial. (HE, obj.20x).

Os exames histopatológicos revelaram lesões nos grupos positivo e negativo frente à sorologia. No grupo positivo, entre as 10 amostras examinadas 3 revelaram lesões renais e uma apresentou lesão hepática, totalizando 4 amostras com lesões. No grupo negativo, 2 amostras apresentaram apenas lesões em um dos rins. Não foram observadas diferenças significativas entre os grupos soropositivo e soronegativo com relação à proporção de lesões histológicas $(p=329)$ (Tabela 2). Nos rins, a principal alteração histológica observada foi a nefrite intersticial que se caracterizou por atrofia glomerular, discreto espessamento da cápsula de Bowman com presença de material proteináceo eosinofílico granular, infiltrado inflamatório mononuclear com presença de macrófagos, linfócitos e raros plasmócitos, discreto a moderado, com necrose do epitélio tubular (Fig. 1). No fígado, as alterações foram discretas, observando-se infiltrado inflamatório mononuclear com presença de macrófagos, linfócitos e plasmócitos, com necrose hepática lobular focalmente localizada. Nenhum animal apresentou lesão em mais de um órgão. Todas as amostras submetidas à técnica Warthin-Starry foram negativas.

\section{DISCUSSÃO}

Os resultados da sorologia indicaram que o provável sorovar prevalente em suínos abatidos no Município de Patos, PB, seja Autumnalis. Boeuist et al. (2005) também encontraram em suínos de granjas tecnificadas maior frequência deanticorpos reagentes para este sorovar do que para os sorovares Pomona, Bratislava, Icterohaemorrhagiae e Tarassovi, frequentemente associados com a infecção em suínos (Michna; CAMPBell, 1969; SANTA Rosa etal., 1969/1970; VAN Til; Dohoo, 1991; Oliveira et al., 1995; Lima, 
1996; Delbem et al., 2002). Os resultados sorológicos também estão de acordo com os obtidos por FAVERO et al. (2002), que identificaram o sorovar Autumnalis como de maior ocorrência em suínos com suspeita clínica de leptospirose no Estado do Ceará. Em contrapartida, os resultados sorológicos contrastam com os obtidos por AzEVEDO et al. (2008a) que, ao realizarem inquérito sorológico em suínos de abate no Município de Patos, $\mathrm{PB}$, encontraram soroprevalência de $33,6 \%$, sendo o sorovar Pomona o mais frequente, em $29,0 \%$ de reações. Essas dissimilaridades podem ser explicadas pelo fato da frequência deapresentação dos diversos sorovares de Leptospira spp. ser dependente da amplitude de deslocamento dos respectivos hospedeiros preferenciais, bem como da intensidade e extensão da produção animal (BLAHA, 1995). Dessa forma pode ocorrer substituição do sorovar Pomona, tradicionalmente mantido pelos próprios suínos, por outros sorovares, neste caso o Autumnalis, apesar do sorovar Icterohaemorrhagiae sermais frequentemente referido como sendo o principal na mudança do perfil epidemiológico da leptospirose suína (SANTA Rosa et al., 1969/1970; CARVAlHo et al., 1990; FAVERO et al., 2002; RAMOS; LILENBAUM, 2002). Sendo o sorovar Autumnalis não adaptado aos suínos, portanto oriundo de infecção acidental (ELLIS, 1992), os resultados sorológicos sugerem maior participação de reservatórios animais de outras espécies, domésticas e/ou sinantrópicas, na cadeia epidemiológica da leptospirose suína na região.

Estudos conduzidos em outras espécies animais abatidas no matadouro público da Cidade de $\mathrm{Pa}-$ tos também revelaram predominância de reações sorológicas para o sorovar Autumnalis. AzEvedo (comunicação pessoal) relatou que, em 100 ovelhas abatidas no mesmo estabelecimento, ocorreram 9\% de soropositividade para a infecção com $44,4 \%$ de frequência para a sorovariedade Autumnalis. Higino (2010) realizou a sorologia de 80 ovinos abatidos e obteve $7,5 \%$ de positividade, com $83,3 \%$ defrequência para a sorovariedade Autumnalis.

A presença da sorovariedade Autumnalis causa preocupação, pois não existe imunidade cruzada entre as diferentes sorovariedades. As vacinas polivalentes disponíveis no mercado são compostas basicamente pelas sorovariedades Icterohaemorrhagiae, Canicola, Hardjo, Grippothyphosa, Pomona, Bratislava e Tarassovi, o que reforça ainda mais a importância da pesquisa continuada no desenvolvimento de novas vacinas antileptospirose mais efetivas e de imunidade mais duradoura, bem como a necessidade da inclusão de novas sorovariedades.

As lesões renais e hepáticas ocorridas em 4 das 10 amostras com títulos de anticorpos $\geq 100$ estudadas são sugestivas, porém, não patognomônicas, da infecção por Leptospira spp. (BASKERVILLE, 1984; HANSON; TRIPATHY, 1986; BAKER et al., 1989; DelBem et al., 2002). As lesões renais observadas no grupo com títulos de anticorpos < 100 foram similares àquelas observadas no grupo com títulos de anticorpos $\geq$ 100. Estes resultados contrastam com os obtidos por HASHIMOTO et al. (2008) que, em suínos abatidos no Paraná, verificaram que animais com lesões de nefrite intersticial apresentaram associação com a soropositividadenaSAM, eque todos os animais que não apresentaram lesões de nefrite intersticial foram soronegativos. Comonão foi constatada positividade na pesquisa direta de detecção do agente, não se pode confirmar que as lesões observadas em ambos os grupos são decorrentes da infecção por Leptospira spp. Uma hipótese seria o animal estar infectado, porém não apresentar título de anticorpos suficientes para caracterizar reação sorológica positiva no ponto de corte estabelecido neste trabalho. Isso pode ocorrer pelo fato das leptospiras serem antígenos com baixa imunogenicidade (ARDUiNo et al., 2004). Ellis et al. (1986) e Delbem et al. (2002) sugeriram que suínos infectados por leptospiras podem apresentar-se negativos na SAM quando se estabelece o título 100 como ponto de corte. FrEITAS (comunicação pessoal) relatou o isolamento de uma estirpe de leptospira a partir de uma fêmea suína considerada negativa na SAM na diluição 1:100.

Outra hipótese sobre a ocorrência das lesões em ambos os grupos, reagentes e não reagentes para Leptospira spp., reflete a possibilidade de terem sido causadas por outros micro-organismos, como foi demonstrado por Drolet et al. (2002) e por MARTíneZ et al. (2005).

Delbem et al. (2002) examinaram 36 fêmeas suínas de descarte, abatidas no Paraná, e também não observaram lesões uterinas e ovarianas sugestivas de leptospirose, o que concorda com os resultados do presente trabalho. GiRo et al. (1998) observaram $32,9 \%$ e $50,1 \%$ de lesões renais e reprodutivas, respectivamente, em fêmeas positivas frente ao sorovar Icterohaemorrhagiae.

AzEVEDO et al. (2008b) utilizaram 76 matrizes suínas de uma granja de ciclo completo do $\mathrm{Mu}$ nicípio de Ibiúna, SP, e verificaram que os sorovares Bratislava e Hardjobovis foram os mais frequentes. Verificaram, também, que a infecção por Leptospira spp., determinada pela detecção de anticorpos, teve impacto negativo no desempenho reprodutivo das fêmeas suínas, com decréscimo no número de nascidos e nascidos vivos, baixo peso ao nascimento, aumento no nascimento de leitões debilitados e mortos, dentre outros.

Os resultados negativos observados pela técnica de Warthin-Starry poderiam ser explicados pela ausência de leptospiras nos tecidos confirmando a hipótese das lesões terem sido causadas por outros agentes; ou então, pela baixa sensibilidade dessa técnica, a qual é dependente da fase da infecção, sendo 
mais sensível na fase aguda onde as leptospiras estão circulantes; da conservação dos tecidos e órgãos e consequentemente da manutenção da morfologia das leptospiras e, ainda, pela interferência de formações inespecíficas decorrentes da própria técnica (ALVES, 1987; SCANZIANi et al., 1989; RADOSTITS et al., 2006; Pescador et al., 2004; Hines, 2007).

No presente trabalho, foi constatada soropositividade de 14,6\% para Leptospira spp. em suínos abatidos no Município de Patos, Paraíba, tendo como principal sorovar reagente o Autumnalis, o que levanta preocupações do ponto de vista de saúde pública, uma vez que profissionais envolvidos no manejo e abate, desses animais, estão expostos ao risco de infecção. Não houve diferença nas frequências de positividade na SAM em animais com e sem lesões histológicas, sugerindo que a ocorrência de lesões de nefrite intersticial não está atrelada aos resultados da SAM.

Com base nos resultados, torna-se importante a conscientização por parte dos produtores acerca da implantação de medidas de prevenção adequadas com o objetivo de impedir, ou pelo menos diminuir, a disseminação da leptospirose em suínos e, consequentemente, bloquear a possível transmissão do agente para os seres humanos. É importante também a conscientização das autoridades sanitárias para a melhoria e manutenção de condições básicas de higiene e segurança durante o abate, bem como para a prática constante de medidas de educação em saúde, com vistas a impedir a possível transmissão do agente para os trabalhadores diretamente envolvidos no abate de suínos.

\section{REFERÊNCIAS}

ALVES, V.A.F.; VIANNA, M.R.; YASUDA, P.H.; DE BRITO, T. Detection of leptospiral antigen in the human liver and kidney using an immunoperoxidase staining procedure. Journal of Pathology, v.159, p.123-131, 1987.

ARDUINO, G.G.C.; GIRIO, R.J.S.; FREIRE, M.M. Anticorpos contra Leptospira spp em bovinos leiteiros vacinados com bacterina polivalente comercial: perfil sorológico frente a dois esquemas de vacinação. Ciência Rural, v.34, n.3, p.865-871, 2004

AZEVEDO, S.S.; SOTO, F.R.M.; MORAIS, Z.M.; PINHEIRO, S.R.; VUADEN, E.R.; BATISTA, C.S.A.; SOUZA, G.O.; DELBEM, A.C.B.; GONÇALES, A.P.; VASCONCELLOS, S.A. Frequency of anti leptospires agglutinins in sows from a swine herd in the Ibiúna Municipality, State of São Paulo, Brazil. Arquivos do Instituto Biológico, São Paulo, v.73, n.1, p.97-100, 2006.

AZEVEDO, S.S.; OLIVEIRA, R.M.; ALVES, C.J.; ASSIS, D.M.; AQUINO, S.F.; FARIAS, A.E.M.; ASSIS, D.M.; LUCENA, T.C.C.; BATISTA, C.S.A.; CASTRO, V.; GE-
NOVEZ, M.E. Prevalence of anti-Leptospira spp. antibodies in swine slaughtered in the public slaughterhouse of Patos city, Paraíba State, Northeast region of Brazil. Arquivos do Instituto Biológico, São Paulo, v.75, n.4, p.517520, 2008a.

AZEVEDO, S.S.; SOTO, F.R.M.; MORAIS, Z.M.; PINHEIRO, S.R.; BATISTA, C.S.A.; VUADEN, E.; VASCONCELLOS, S.A. The effects of the leptospiral infection on reproductive performance in sows. Veterinarski Arhiv, v.78, n.1, p.13-21, 2008b.

BAKER, T.F.; MCEWEN, S.A.; PRESCOTT, J.F. The prevalence of leptospirosis and its association with multifocal interstitial nephritis in swine at slaughter. Canadian Journal of Veterinary Research, v.53, p.290-294, 1989.

BASKERVILLE, A. Histopathological aspects of diagnosis of leptospirosis. In: ELLIS, W.A.; LITTLE, T.W.A. (Ed.). The Present State of Leptospirosis Diagnosis and Control. Dordrecht: Martinus Nijhoff Publishers, 1984. p.33-43.

BLAHA, T. Epidemiología especial veterinaria. Zaragoza: Acribia, 1995. 529p.

BOQUIST, S.; HOTHI, U.T.; MAGNUSSON, A.A. Annual variations in leptospira seroprevalence among sows in southern Vietnam. Tropical Animal Health and Production, v.6, p.443-449, 2005.

CARVALHO, L.F.O.S.; CARVALHO, M.B.; GIRIO, R.J.S. Investigação sorológica de fêmeas suínas descartadas para abate por transtornos diversos. Ciência Veterinária, v.4, n.2, p.6-8, 1990.

CHAPPEL, R.J.; PRIME, R.W.; MILLAR, B.D.; MEAD, L.J.; JONES, R.T.; ADLER, B. Comparison of diagnostic procedures for porcine leptospirosis. Veterinary Microbiology, v.30, p.151-163, 1992.

DELBEM, A.C.B.; BRACARENSE, A.P.F.R.L.; MÜLLER, E.E.; OLIVEIRA, R.C. Leptospirosis in slaughtered sows: serological and histopathological investigation. Brazilian Journal of Microbiology, v.33, p.174-177, 2002.

DROLET, R.; RIBOTTA, M.; HIGGINS, R.; D'ALLAIRE, R.; LAROCHELLE, S.; MAGAR, R. Infectious agents identified in pigs with multifocal interstitial nephritis at slaughter. Veterinary Record, v.150, p.139-143, 2002.

ELLIS, W.A. Leptospirosis in pig. Pig Veterinary Journal, v.28, p.24-34, 1992.

ELLIS, W.A. Leptospirosis. In: STRAW, B.E.; D’ALLAIRE, S.; MENGELING, W.L.; TAYLOR, D.J.; LEMAN, A.D. (Ed.). Diseases of swine. 9.ed. Iowa: Blackwell Publishing, 2006. p.691-700.

ELLIS, W.A.; MCPARLAND, P.J.; BRYSON, D.G.; THIERMANN, A.B.; MONTGOMERY, J. Isolation of 
leptospires from the genital tract and kidneys of aborted sows. Veterinary Research, v.118, p.294-295, 1986.

FAINE, S. Guidelinis for the control of Leptospirosis. Geneva: World Health Organization, 1982. (Offset Publication 6).

FAINE, S.; ADLER, B.; BOLIN, C.; PEROLAT, P. Leptospira and Leptospirosis. 2.ed. Melbourne: Medisci, 1999. 272p.

FARIA, E.J.; RIBEIRO, M.F.B.; SANTOS, J.L.; DALE, R.; SALCEDO, J.H.P. Frequência de aglutininas anti-leptospiras em soros sanguíneos de suínos das microrregiões de Viçosa e Ponte Nova, MG. Arquivo Brasileiro de Medicina Veterinária e Zootecnia, v.41, p.381-388, 1989.

FAVERO, A.C.M.; PINHEIRO, S.R.; VASCONCELLOS, S.A.; MORAIS, Z.M.; FERREIRA, F.; FERREIRA NETO, J.S. Sorovares de leptospiras predominantes em exames sorológicos de bubalinos, ovinos, caprinos, eqüinos, suí-nos e cães de diversos estados brasileiros. Ciência Rural, v.32, p.613-619, 2002.

GIRIO, R.J.S.; DIAS, H.L.T.; MATHIAS, L.A.; SANTANA, A.E.; ALESSI, A.C. Alterações reprodutivas, hematológicas e anatomopatológicas em fêmeas suínas com títulos de anticorpos contra Leptospira interrogans sorotipo icterohaemorrhagiae. Revista Brasileira de Ciência Veterinária, v.5, n.3, p.99-103, 1998.

HANSON, L.E.; TRIPATHY, D.N. Leptospirosis, In: LEMAN, A.D.; STRAW, B.; GLOCK, D.; MENGELING, W.L.; PENNY, R.H.C.; SCHOLL, E. (Ed.). Diseases of swine. 6.ed. Ames: Iowa State University Press, 1986. p.591-599.

HASHIMOTO, V.Y.; ANZAI, E.K.; LIMA, B.A.C.; SILVA, F.G.; ALVES, L.A.; FREIRE, R.L.; TELES, O.S.; GARCIA, J.L.; MULLER, E.E.; FREITAS, J.C. Associação entre as lesões renais microscópicas e a presença de anticorpos contra Leptospira spp em suínos aparentemente sadios, abatidos em frigorífico da região norte do estado do Paraná. Semina: Ciências Agrárias, v.29, p.875-880, 2008.

HIGINO, S.S.S.; AZEVEDO, S.S.; ALVES, C.J.; FIGUEIREDO, S.M.; SILVA, M.L.C.R.; BATISTA, C.S.A. Frequência de leptospirose em ovinos abatidos no município de Patos, Paraíba. Arquivos do Instituto Biológico, São Paulo, v.77, n.3, p.525-527, 2010.

HINES, M.T. Leptospirosis, In: SELLON, D.C.; LONG, M.T. (Ed.). Equine infectious diseases. Saint Louis: Saunders Elsevier, 2007. p.301-309.

JaCKSON, P.G.G.; CockCrOFt, P.D. Handbook of Pig Medicine. Edinburgh: Saunders Elsevier, 2007. 308p.

LARSSON, C.E.; YASUDA, P.H.; SANTA ROSA, C.A.; COSTA, E.O. Leptospirose suína: inquérito sorológico e bacteriológico em municípios dos estados de São Paulo, do Paraná e de Santa Catarina. Revista da Faculdade de Medicina Veterinária e Zootecnia da Universidade de São Paulo, v.21, p.43-50, 1984.

LEFEBVRE, R.B. Spiral-curved organism. V. Leptospira. In: HIRSH, D.C.; MACLACHLAN, N.J.; WALKER, R.L. (Ed.). Veterinary microbiology. 2.ed. Ames: WileyBlackwell, 2004. p.148-153.

LIMA, P.C.R. Diagnóstico de leptospirose em suínos no Rio Grande do Sul: exames laboratoriais em fêmeas suínas descartadas em frigoríficos e em reprodutores de granjas com e sem problemas de reprodução, durante o período de um ano. Arquivos da Faculdade de Veterinária da Universidade Federal do Rio Grande do Sul, v.24, p.119121, 1996.

MAILLOUX, M. Leptospirosis = zoonoses. International Journal of Zoonoses, v.78, p.1158-1159, 2001.

MARTÍNEZ, J.; SEGALÉS, J.; ADUREZ, G.; ATXAERANDIO, R.; JARO, P.; ORTEGA, J.; PERES, B.; CORPA, J.M. Pathological and aetiological studies of multifocal interstitial nephritis in wasted pigs at slaughter. Research in Veterinary Science, v.81, p.92-98, 2005.

MICHNA, S.W.; CAMPBELL, R.S.F. Leptospirosis in pigs: epidemiology, microbiology and pathology. Veterinary Record, v.84, p.135-138, 1969.

MYERS, D. Leptospirosis: manual de métodos para el diagnostico de laboratório. Buenos Aires: Centro Panamericano de Zoonosis, OPS/OMS, 1985. (Nota Técnica 30).

OLIVEIRA, S.J. Leptospirose em suínos. A Hora Veterinária, v.7, p.5-8, 1988.

OLIVEIRA, S.J.; LIMA, P.C.R.; BARCELLOS, D.E.S.N.; BOROWSKI, S.M. Sorologia para diagnóstico de leptospirose em suínos no Rio Grande do Sul: resultados obtidos de granjas com e sem problemas de reprodução. Pesquisa Agropecuária Gaúcha, v.1, p.263-267, 1995.

OLIVEIRA, S.J. Nova ameaça à reprodução em suínos, além da leptospirose? A Hora Veterinária, v.19, p.87-90, 1999.

PESCADOR, C.A.; CORBELLINI, L.G.; LORETTI, A.P.; WUNDER JÚNIOR, E.; FRANTZ, F.J.; DRIEMEIER, D. Aborto eqüino por Leptospira sp. Ciência Rural, v.34, p.271-274, 2004.

RADOSTITS, O.M.; GAY, C.C.; BLOOD, D.C.; HINCHCLIFF, K.W. Veterinary Medicine: a textbook of the diseases of cattle, horses, sheep, pigs and goats. 10.ed. Philadelphia: W.B. Saunders, 2006. 2065p.

RAMOS, A.C.F.; LILENBAUM, W. Fatores que influenciam na ocorrência de aglutininas anti-leptospira em suínos de criação tecnificada do estado do rio de janeiro. Revista Brasileira de Medicina Veterinária, v.24, p.20-29, 2002. 
SANTA ROSA, C.A.; CASTRO, A.F.P.; SILVA, A.S.; TERUYA, J.M. Nove anos de leptospirose no instituto biológico de São Paulo. Revista do Instituto Adolfo Lutz, v.29/30, p.19-27, 1969/1970.

SCANZIANI, E.; SIRONI, G.; MANDELI, G. Immunoperoxidase studies on leptospiral nephritis of swine. Veterinary Pathology, v.26, p.442-444, 1989.

SHIMABUKURO, F.H.; DOMINGUES, P.F.; LANGONI, H.; SILVA, A.V.; PINHEIRO, J.P.; PADOVANI, C.R. Pesquisa de suínos portadores renais de leptospiras pelo isolamento microbiano e reação em cadeia pela polimerase em amostras de rins de animais sorologicamente positivos e negativos para leptospirose. Brazilian Journal of Veterinary Research and Animal Science, v.40, p.243-253, 2003.

SIEGEL, S.; CASTELLAN JUNIOR, N.J. Estatística nãoparamétrica para as ciências do comportamento. 2.ed. Porto Alegre: Artmed, 2006. 448p.

SOBESTIANSKY, J.; BARCELLOS, D.; MORES, N.; CARVALHO, L.F.; OLIVEIRA, S. Clínica e Patologia
Suína. 2.ed. Goiânia: Universidade Federal de Goiás, 1999. 464p.

TOLOSA, E.M.C.; RODRIGUES, C.J.; BEHMER, O.A.; FREITAS NETO, A.G. Manual de técnicas para histologia normal e patológica. Barueri: Manole, 2003. 331p.

VAN TIL, L.D.; DOHOO, I.R. A serological survey of leptospirosis in prince edward island swine herds and its association with infertility. Canadian Journal of Veterinary Research, v.4, p.352-355, 1991.

WANG, Q.K.; ZHANG, J.G.; DU, R.; WANG, S.Z.; WILSON, $\mathrm{P}$. Observations of renal histopathology associated with leptospirosis in farmed deer. Journal of Jilin Agricultural University, v.21, p.63-65, 1999.

YOUNG, B.J. A reliable method for demonstrating spirochaetes in tissue sections. Journal of Medical Laboratory Technology, v.26, p.248-252, 1969.

Recebido em 22/9/11

Aceito em $9 / 1 / 13$ 